\title{
$5 \mathrm{~V}$ input level shifter circuit for IGZO thin-film transistors
}

\author{
HongKyun Lym ${ }^{1}$, HwanSool Oh${ }^{1}$, JaeEun Pi $^{2}$, Chi-Sung Hwang ${ }^{2}$, \\ SangHee Ko Park ${ }^{3}$, and KeeChan Park ${ }^{1 \mathrm{a})}$ \\ ${ }^{1}$ Department of Electronics Engineering, Konkuk University, \\ 120 Neungdong-ro, Gwangjin-gu, Seoul 143-701, Korea \\ ${ }^{2}$ Oxide Research Team, Electronics and Telecommunications Research Institute, \\ 218 Gajeong-ro, Yuseong-gu, Daejeon 305-700, Korea \\ ${ }^{3}$ Department of Materials Science and Engineering, Korea Advanced Institure of \\ Science and Technology, 291 Daehak-ro, Yuseong-gu, Daejeon 305-701, Korea \\ a)keechan@konkuk.ac.kr
}

\begin{abstract}
A $5 \mathrm{~V}$ input level shifter circuit based on depletion-mode In-Ga-Zn-O thin-film transistors (TFT) worked up to $100 \mathrm{kHz}$. By employing metal-insulator-semiconductor (MIS) active capacitor, we enhanced the bootstrapping effect and reduced the rise time of the output signal. SPICE simulation results showed that the proposed level shifter worked for wide threshold voltage range from $-2 \mathrm{~V}$ to $+1 \mathrm{~V}$ and the fabricated circuit exhibited the propagation delay $t_{\mathrm{plh}}$ and $t_{\mathrm{phl}}$ of 0.6 usec and $0.3 \mu \mathrm{sec}$ respectively.
\end{abstract}

Keywords: $5 \mathrm{~V}$ input, level shifter, depletion-mode, oxide TFT, active capacitor

Classification: Electron devices, circuits, and systems

\section{References}

[1] C. H. Oh, H. J. Shin, W. J. Nam, B. C. Ahn, S. Y. Cha and S. D. Yeo: SID Symp. Dig. Tech. Papers (2013) 239.

[2] J. Song, J. H. Lim, B. D. Ahn and J. Lee: SID Symp. Dig. Tech. Papers (2013) 93.

[3] S. H. Choi and M. K. Han: IEEE Elec. Dev. Lett. 34 (2013) 771. DOI:10.1109/ LED.2013.2256457

[4] F. H. Chen, T. M. Pan, C. H. Chen, J. H. Liu, W. H. Lin and P. H. Chen: IEEE Elec. Dev. Lett. 34 (2013) 635. DOI:10.1109/LED.2013.2248115

[5] N. Morosawa, Y. Ohshima, M. Morooka, T. Arai and T. Sasaoka: J. Soc. Inf. Disp. 20 (2012) 47. DOI:10.1889/JSID20.1.47

[6] J. E. Pi, M. K. Ryu, C. S. Hwang, S. H. Yang, S. H. K. Park, S. M. Yoon, H. K. Leem, Y. K. Kim, J. D. Kim, H. S. Oh and K. C. Park: IEEE Elec. Dev. Lett. 33 (2012) 1144. DOI:10.1109/LED.2012.2200873

[7] M. W. Oh, H. G. Leem, S. M. Yoon, C. W. Byun, S. H. K. Park, H. S. Oh and K. C. Park: Electron. Lett. 47 (2011) 378. DOI:10.1049/el.2011.0022

[8] B. Kim, S. C. Choi, S. H. Kuk, Y. H. Jang, K. S. Park, C. D. Kim and M. K. Han: IEEE Elec. Dev. Lett. 32 (2011) 167. DOI:10.1109/LED.2010.2093505

[9] S. Y. Kim, J. D. Kim, Y. K. Kim, H. K. Lym, J. T. Kim, H. S. Oh, J. E. Pi, 
M. K. Ryu, C. S. Hwang, S.-H. K. Park, B. G. Yu and K. C. Park: IEEE/OSA

J. Disp. Technol. 9 (2013) 71. DOI:10.1109/JDT.2012.2237159

\section{Introduction}

Recently thin-film transistors (TFT) employing metal-oxide semiconductors such as In-Ga-Zn-O (IGZO) are expanding their application because they exhibit low process cost compared with the low-temperature polycrystalline silicon (LTPS) TFT and superior stability and higher on-current than the amorphous silicon (a-Si) TFT. They are suitable for high-resolution activematrix liquid-crystal display (AMLCD) and large-area active-matrix organic light-emitting diode (AMOLED) display [1, 2].

However the oxide TFT operates only as n-channel field-effect transistor and it is difficult to control the threshold voltage $\left(\mathrm{V}_{\mathrm{T}}\right)$ as intended. They often exhibits depletion-mode characteristics due to narrow process window and by external influences such as illumination and bias stress $[3,4,5]$. As a result, a considerable amount of current may flow at zero gate-to-source bias $\left(\mathrm{V}_{\mathrm{GS}}\right)$. Due to the possible negative threshold voltage $\left(\mathrm{V}_{\mathrm{T}}\right)$ of the oxide TFTs, it is not desirable to utilize conventional circuit scheme when we integrate the driving circuitry on a display panel. Accordingly several new circuit structures have been devised based on the depletion characteristics of the metal-oxide TFTs $[6,7,8,9]$. In this letter, we report a new level shifter circuit that is compatible with the $5 \mathrm{~V}$ TTL(transistor-transistor logic)-level input and depletion-mode oxide TFTs.

Fig. 1 shows the circuit structure and the timing diagram of the level shifter. It generates a $20 \mathrm{~V}$ digital signal from two $5 \mathrm{~V}$ input signals, i.e. $\mathrm{V}_{\text {IN }}$ and $\mathrm{V}_{\text {INB }}$. So it can be used in generating the control signals, e.g. start and clocks of a gate driver in the active-matrix display from the $5 \mathrm{~V}$ TTL-level signals of a driver IC. This circuit is composed only of $n$-channel oxide TFTs, so it is difficult to pull-up the output voltage up to $\mathrm{V}_{\mathrm{DD}}(20 \mathrm{~V})$. Therefore
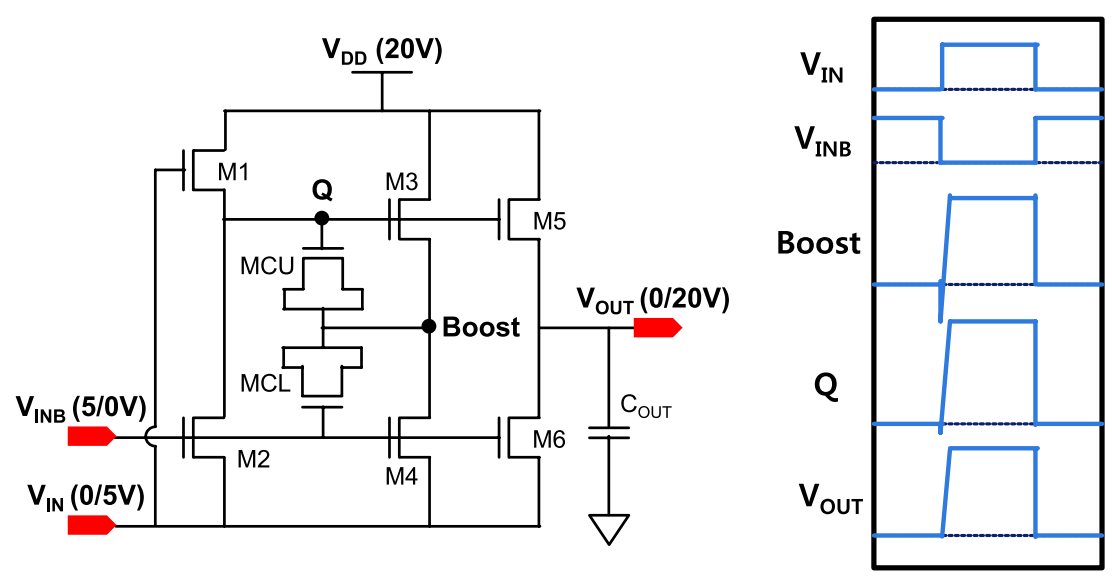

Fig. 1. Circuit structure and timing diagram of the level shifter. 
bootstrapping effect is used to turn on the pull-up TFT M3 and M5 even when the output voltage reaches $\mathrm{V}_{\mathrm{DD}}$ by pushing up the $\mathrm{Q}$ node above $\mathrm{V}_{\mathrm{DD}}$.

The $\mathrm{Q}$ node voltage may fall while $\mathrm{V}_{\mathrm{IN}}$ keeps $5 \mathrm{~V}$ due to large zero-bias current of M2 if M2 is turned off with zero $\mathrm{V}_{\mathrm{GS}}$. However our circuit applies negative $\mathrm{V}_{\mathrm{GS}}$, i.e. $-5 \mathrm{~V}$ to $\mathrm{M} 2$ when $\mathrm{V}_{\mathrm{IN}}$ is $5 \mathrm{~V}$ and $\mathrm{V}_{\mathrm{INB}}$ is $0 \mathrm{~V}$, which suppresses the leakage current through M2 and keeps the $\mathrm{Q}$ node voltage above $\mathrm{V}_{\mathrm{DD}}$. The metal-insulator-semiconductor (MIS) active capacitors MCU and MCL enhance the pull-up speed by varying the capacitance depending on the situation during the transient period.

\section{Operation of level shifter}

Fig. 2 shows the transient response of each node voltage in the level shifter circuit when $\mathrm{V}_{\mathrm{T}}$ of the TFTs is $0 \mathrm{~V}$. At $\mathrm{T} 1, \mathrm{~V}_{\text {IN }}$ rises from $0 \mathrm{~V}$ to $5 \mathrm{~V}$ while $\mathrm{V}_{\text {INB }}$ falls from $5 \mathrm{~V}$ to $0 \mathrm{~V}$. At this moment MCL has large capacitance because it has been turned on by the previous bias condition, i.e. $\mathrm{V}_{\mathrm{GS}}=5 \mathrm{~V}$. Therefore the Boost node is pulled down by strong capacitive coupling with $\mathrm{V}_{\text {INB }}$. However the capacitive coupling between the $\mathrm{Q}$ node and the Boost node is minimized because MCU has been almost turned off by $\mathrm{V}_{\mathrm{GS}}=0 \mathrm{~V}$. This phenomenon is graphically shown in Fig. 3(a) and is verified in the SPICE simulation results of Fig. 2. As a result, $\mathrm{V}_{\mathrm{GS}}$ of $\mathrm{M} 3$ is higher than $0 \mathrm{~V}$ and M3 is slightly turned on at T1.

At the beginning of $\mathrm{T} 2$ period, the $\mathrm{Q}$ node voltage rises faster than the $\mathrm{B}$ node because $\mathrm{M} 1$ is more strongly turned on by $\mathrm{V}_{\mathrm{IN}}=5 \mathrm{~V}$ than $\mathrm{M} 3$ as shown in Fig. 3(b) and Fig. 2. This effect further increases the VGS of M3. Soon the $\mathrm{Q}$ node voltage approaches $5 \mathrm{~V}$ and the current through M1 decreases to

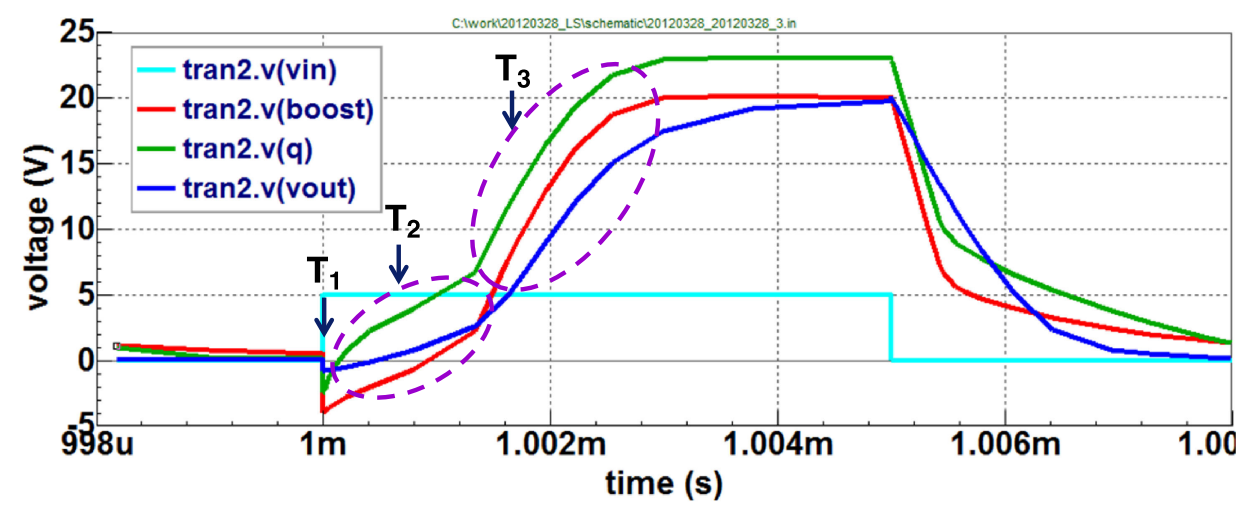

Fig. 2. Transient response of each node voltage in the level shifter
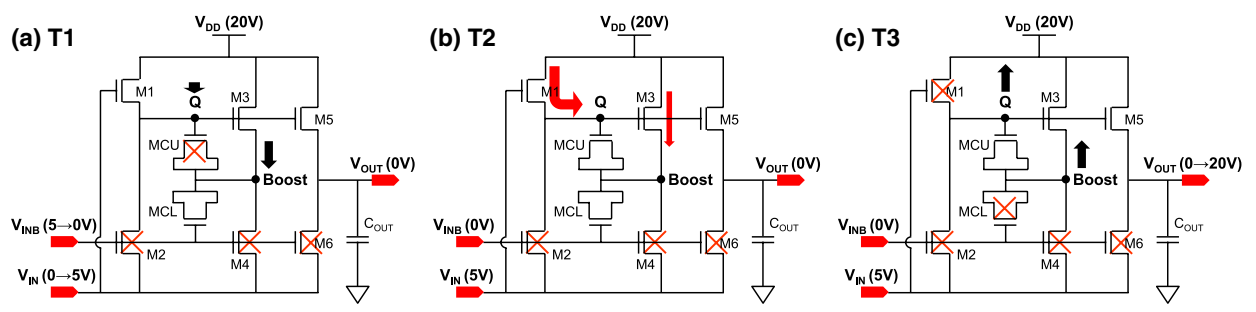

Fig. 3. Operation of each TFT during pull-up process. 
below the current through M1. At this moment M3 is considerably turned on $\left(\mathrm{V}_{\mathrm{GS}} \sim 5 \mathrm{~V}\right)$ and the current through $\mathrm{M} 3$ raises the voltage of the Boost node. Accordingly MCU is also turned on and has large capacitance. Therefore the Q node is pushed up effectively by capacitive coupling with the Boost node and the voltage rising speed of the $\mathrm{Q}$ and the Boost nodes become similar as shown in Fig. 2. However the voltage rising speed by the bootstrapping effect is not so high because the large capacitance of MCL restrict the voltage rising of the Boost node.

At the end of $\mathrm{T} 2$ period, the Boost node voltage exceeds $\mathrm{V}_{\text {INB }}, 0 \mathrm{~V}$ and so MCL is turned off. Therefore the capacitance of MCL decreases substantially and the voltage rising speed of the Boost node increases noticeably as shown in Fig. 2. During T3 period, the Q node and the Boost node voltages rise fast by the bootstrapping effect with large MCU and small MCL. It should be noted that the bootstrapping speed is enhanced by the capacitance variation of the two active capacitors, MCU and MCL.

Once the Q node is boosted up, it is maintained stably even though the TFTs exhibit depletion-mode characteristics because the two switch TFTs, $\mathrm{M} 1$ and $\mathrm{M} 2$ are turned off with negative $\mathrm{V}_{\mathrm{GS}}$. When $\mathrm{V}_{\mathrm{IN}}$ falls to $0 \mathrm{~V}$ and $\mathrm{V}_{\text {INB }}$ rises to $5 \mathrm{~V}$, the pull-down TFTs, M2, M4, and M6 are turned on and the $\mathrm{Q}$ node and the Boost nodes are pulled down to $0 \mathrm{~V}$.

\section{Results}

We used SmartSpice in simulating the operation of the level shifter. Fig. 4 shows the simulation results the level shifter for various TFT $\mathrm{V}_{\mathrm{T}}$ values. For each $\mathrm{V}_{\mathrm{T}}$ value, it is assumed that all the TFTs in the circuit have same $\mathrm{V}_{\mathrm{T}}$. Input pulse duration is $5 \mu \mathrm{sec}$. This corresponds to $100 \mathrm{kHz}$ operation when $50 \%$ duty is assumed. The circuit works even though $\mathrm{V}_{\mathrm{T}}$ is $-2 \mathrm{~V}$. As $\mathrm{V}_{\mathrm{T}}$ falls below $-2 \mathrm{~V}$, the output low level, though not shown here, rises gradually. Propagation delay and rise/fall time increase as $\mathrm{V}_{\mathrm{T}}$ increases.

We fabricated the designed level shifter using the IGZO TFTs as shown in Fig. 5. Fig. 6 shows the measured input and output waveforms of the level shifter working at $100 \mathrm{kHz}$ input signal frequency. In the fabricated circuit, $\mathrm{V}_{\mathrm{T}}$ of the TFTs was not so uniform. For Fig. 6(a), the sample TFTs around the

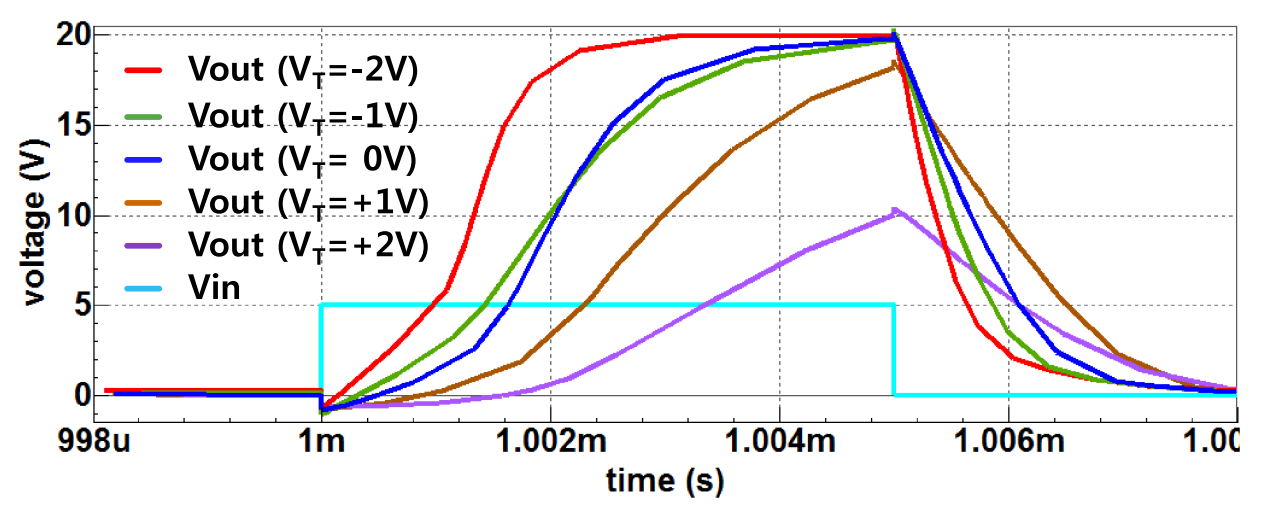



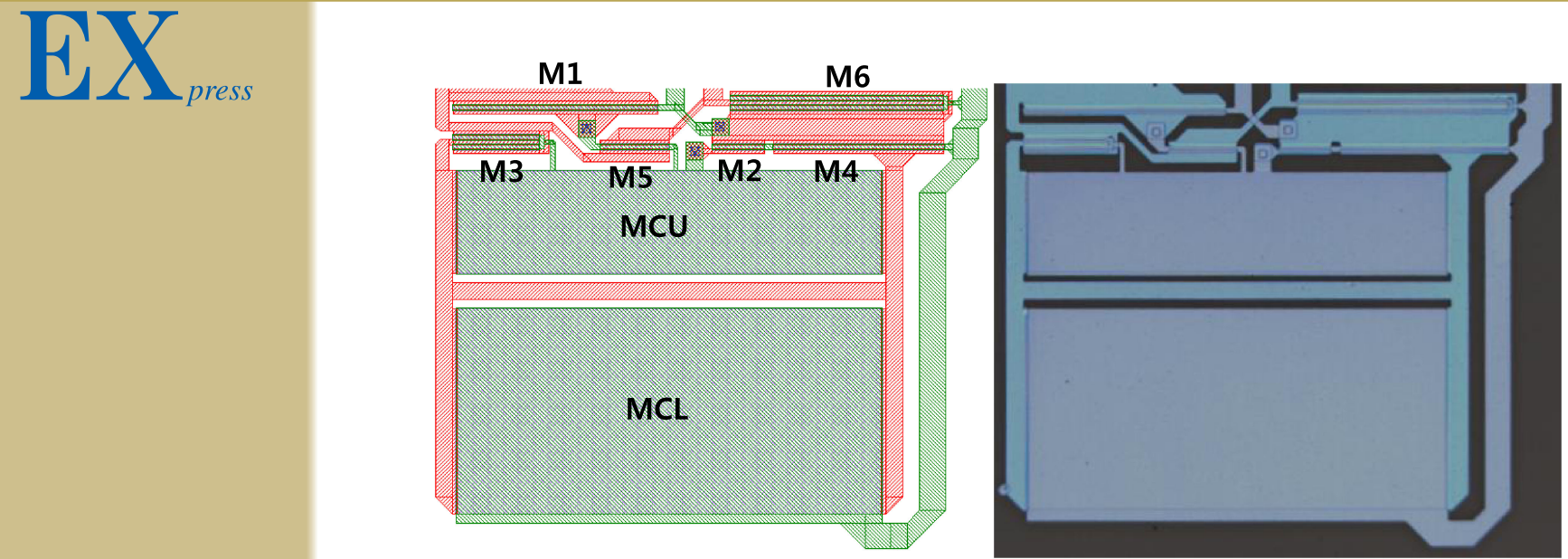

Fig. 5. Layout and photograph images of the level shifter.
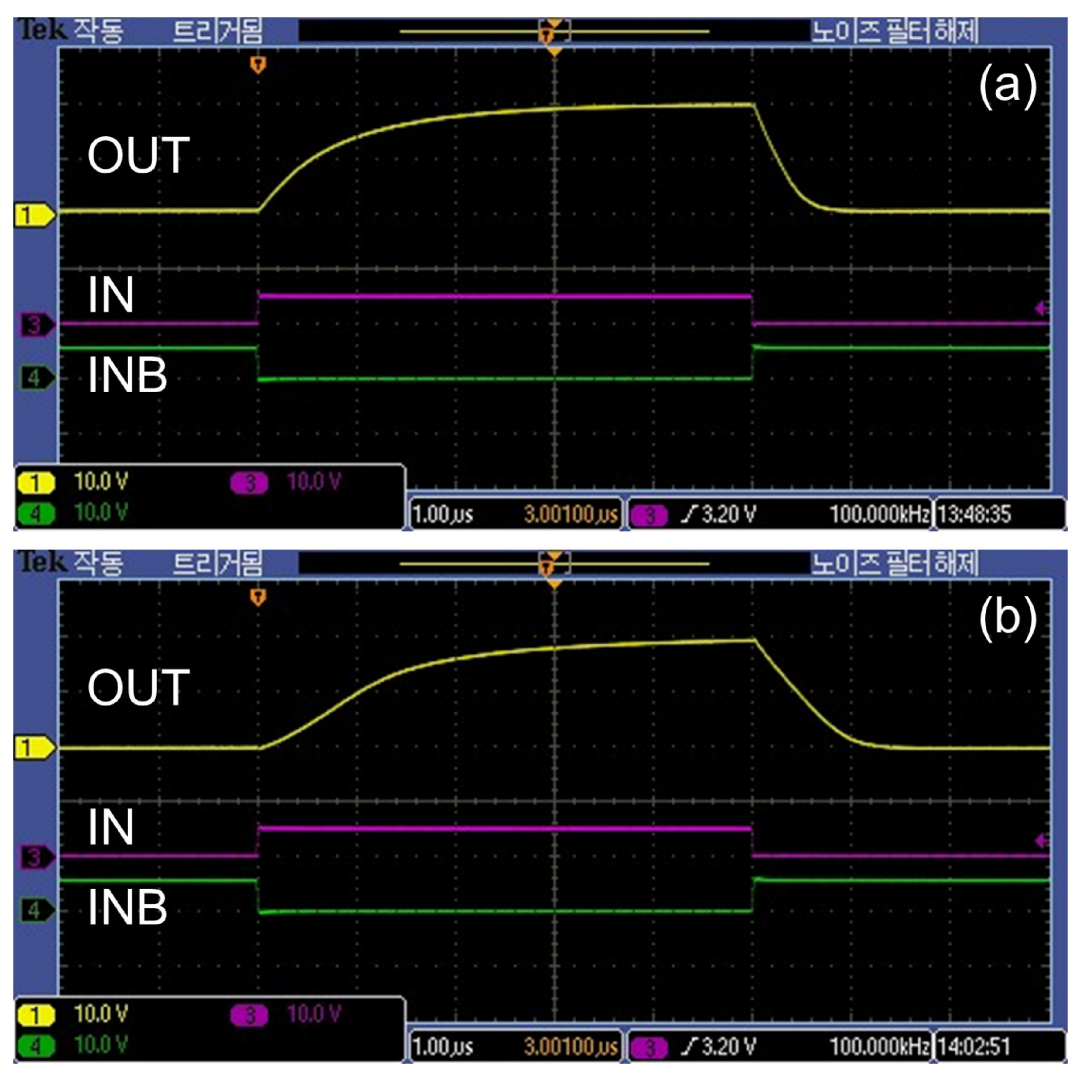

Fig. 6. Measured results of the fabricated level shifter with IGZO TFT process. (a) $\mathrm{V}_{\mathrm{T}} \sim-2 \mathrm{~V}$. (b) $\mathrm{V}_{\mathrm{T}} \sim-1 \mathrm{~V}$. Input pulse duration is 5 usec.

circuit exhibited $\mathrm{V}_{\mathrm{T}}$ of $-2 \mathrm{~V}$ or so, while for Fig. $6(\mathrm{~b}), \mathrm{V}_{\mathrm{T}}$ was around $-1 \mathrm{~V}$. Therefore the propagation delay $t_{p l h}$ and $t_{p h l}$ are as small as $0.6 \mu s e c$ and $0.3 \mu \mathrm{sec}$ respectively in Fig. 6(a), while they are as large as $1.1 \mu \mathrm{sec}$ and 0.5 usec in Fig. 6(b).

\section{Conclusion}

We have developed a $5 \mathrm{~V}$ input level shifter circuit suitable for the n-channel metal-oxide TFT characteristics. This circuit generates a $20 \mathrm{~V}$ output signal 
even though $\mathrm{V}_{\mathrm{T}}$ of the TFTs varies from $-2 \mathrm{~V}$ to $+1 \mathrm{~V}$. The fabricated IGZO level shifter worked successfully at $100 \mathrm{kHz}$ input signal frequency with the propagation delay less than 1 usec. The high pull-up speed despite the disadvantage of n-channel transistor circuit, is owing to the enhanced bootstrapping effect of the active MIS capacitors.

\section{Acknowledgments}

This work was written as part of Konkuk University's research support program for its faculty on sabbatical leave. 